deposition in Antarctica were also presented. Further, the role of solar forcing on climate was discussed, with emphasis on the southern westerlies. Human-climate interactions during the Holocene were discussed for Europe and central Asia, as were large-scale changes in circulation of the Atlantic Ocean for the Holocene and during Terminations I and II. Research into biogeochemical feedbacks to understand the formation of sapropels in the Mediterranean during the Holocene, were also presented. Additionally, previous interglacials were highlighted with regard to carbon cycle dynamics and orbitally induced trends in sea-surface temperature.

The program was complemented with invited presentations by Julian Sachs (on Holocene changes in the position of the Pacific rainbelt), Pinxian Wang (on the global monsoon system and its variability over a range of timescales) and Jürg Luterbacher (on perspectives of high-resolution climate reconstructions for the last millennium).

The next status seminar for the program will be held in spring 2010.

\title{
Compiling records of Holocene erosion and sediment transport
}

\section{LUCIFS Workshop - Christchurch, New Zealand, 6-10 December 2008}

\section{Nick Preston}

School of Geography, Environment and Earth Sciences, Victoria University of Wellington, New Zealand; Nick.Preston@vuw.ac.nz

A general meeting of the PAGES Focus 4 (PHAROS) Working Group "LUCIFS" took place in Christchurch, New Zealand, on the campus of Canterbury University. Richard Dikau (University of Bonn, Germany) as Chair, and the local organizer, Nick Preston (Victoria University of Wellington, New Zealand), were pleased to welcome 30 participants from 13 countries. The workshop provided an opportunity for presentation of recent research results and for discussion of a range of topical issues.

The workshop followed a joint meeting of the International Association of $\mathrm{Hy}$ drological Sciences and the International Commission on Continental Erosion, with many participants attending both meetings. A field trip led by Nick Preston and Nicola Litchfield (GNS Science, New Zealand) provided a break between the meetings. The field trip traveled to Mount Cook at the heart of New Zealand's Southern Alps and followed a source-to-sink route from the headwaters down through the catchment of the Waitaki River, focusing on the relative impacts on sediment flux of anthropogenic modifications and the glacial/post-glacial transition.

The schedule consisted of 18 oral presentations spread over two days. Many presentations highlighted the importance of human land use as the dominant control on erosion and sedimentation in diverse environments, ranging from central Europe to South America and New Zealand. It is therefore important to be able to reconstruct population densities through time, which the prehistoric archeologists from the University of Cologne have been able to do, suggesting that the pronounced human impacts result from lower population densities than have been conventionally estimated. Nevertheless, over longer temporal scales, human impacts must be considered to intensify natural trends, as

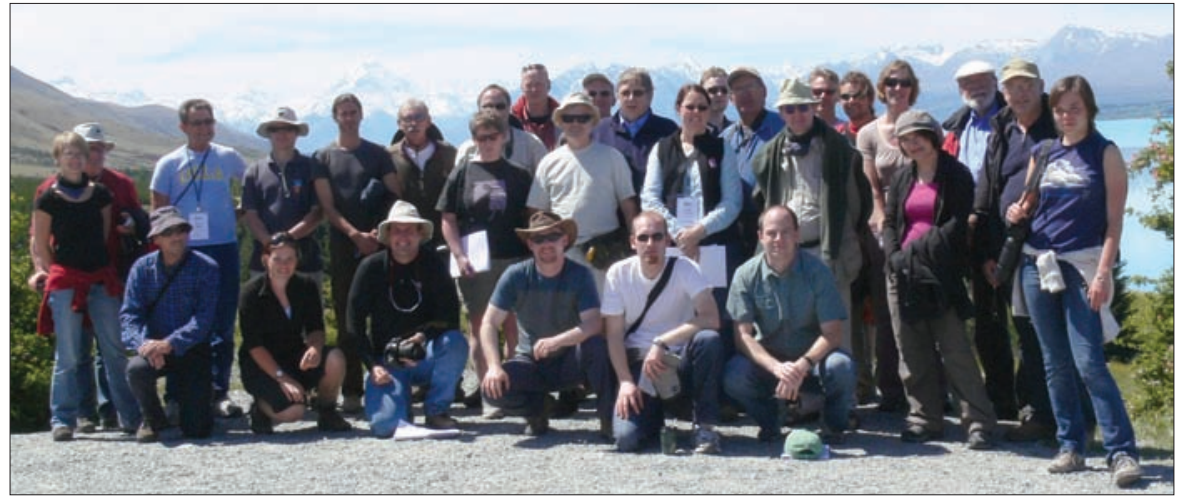

Figure 1: Participants of the LUCIFS general meeting

was shown for Middle East desertification. Similarly, research from the Rhine catchment shows that the behavior of the geomorphic system itself offers a further level of complexity. A number of keynote talks provided the basis for subsequent discussion group sessions. On the second and third days of the workshop, the meeting separated into small working groups to discuss the following issues:

- Defining a "LUCIFS method": Identification and elaboration of the systematic context in which LUCIFS researchers characterize fluvial systems (trajectories of change, spatial and temporal dis/connectivity, scale issues, etc.).

Methodological considerations: Techniques for reconstruction of past landscape behavior using multiple and diverse environmental proxies.

- Development of a LUCIFS database: Structure, metadata, content.

These structured discussions helped to clarify key issues for further research, which were presented to the whole group of participants in a plenary session. White papers will be produced, summarizing the discussions and the issues that they raised, and will initially be published on the LUCIFS website.

A final discussion addressed future LUCIFS research strategies and the group's role within the overarching PHAROS research focus. While LUCIFS research will continue with its emphasis on understanding the behavior of fluvial sediment redistribution systems, particularly as influenced by humans, members of the group will also contribute to the PHAROS "Soil and Sediment" and "Carbon" Themes (see www.pages-igbp.org/science/focus4 .html for more information on these).

Richard Dikau expressed the wish to pass on the leadership of the group, and the gathered membership decided to make a number of changes to the organizational structure. Nick Preston was elected as Chair and Thomas Hoffmann to fill the dual role of Secretary and Co-Chair. They will be joined by a flexible Steering Committee, consisting of Andreas Lang, Gilles Erkens, Jochen Schmidt and Mike Page. Membership of the Committee will change to reflect the nature of the group's activities. In addition, those members who have previously served on the Committee will be invited to continue their input by serving on an Advisory Board.

People interested in LUCIFS activities are invited to visit the LUCIFS website (http://gidimap.gub.uni-bonn.de:9080/ lucifs/) for further information.

\section{(2)}

